\title{
Black Woodpecker Dryocopus martius habitat selection in the Italian Alps: implications for conservation in Natura 2000 network
}

\author{
ANDREA R. PIROVANO and GIOVANNI ZECCA
}

\section{Summary}

The Black Woodpecker Dryocopus martius is the largest woodpecker of the Palearctic Region and it has been recognised as a keystone species whose presence provides critical resources to secondary cavity-users in European forest ecosystems. Here we investigate cavity tree and foraging-habitat selection of Black Woodpecker in three natural parks located in the central and eastern Italian Alps and included in the Natura 2000 network. A total of 94 cavity trees were identified, showing a minimum diameter of $35 \mathrm{~cm}$ and a mean diameter of $51 \mathrm{~cm}$. We counted 30 active nests, but only $40 \%$ were newly excavated. Silver fir Abies alba and larch Larix decidua were preferred as cavity trees, with silver fir also associated with habitat surrounding the cavity trees. Norway spruce Picea abies and Silver fir were found to be positively associated with the surroundings of feeding sites. Logistic regression models identified the average diameter at breast height and the average tree crown height as significant predictors, positively associated with both cavity trees (AUC: o.988) and cavity tree plots (AUC: o.866). Also, the total volume of dead logs and the percentage of understorey cover turned out to be significant predictors of feeding sites, showing a positive and a negative association, respectively (AUC: 0.708). Cross validation of logistic regression models indicated that only cavity tree models can be considered useful tools in conservation practice. Overall, our results indicated that the Black Woodpecker behaves like an opportunist when choosing feeding sites. On the other hand, our results also indicate that the Black Woodpecker clearly behaves as a demanding species when it selects cavity trees, showing a hierarchical pattern in habitat selection and a marked preference for large trees with high crown height. We discuss the implications of our results for the conservation of the Black Woodpecker in Natura 2000 alpine sites.

\section{Introduction}

Nowadays careful planning of environmental management strategies is unanimously recognised as a keystone to conservation practice. The European Union has placed the creation of a coherent European ecological network of protected areas called Natura 2000 at the centre of its biodiversity conservation policy. The Natura 2000 network aims to maintain and, where appropriate, to restore all the wildlife components listed in the Habitats Directive 92/43/CEE and Birds Directive 79/409/ $\mathrm{CEE}$, through the production of proper management plans that take into account scientific, economic, social and cultural considerations. However, the need for accurate and scientifically based procedures required to define maintenance priorities and formulate realistic conservation strategies both for species and habitats (European Commission 2003), is often in conflict with the scarce availability of resources (Rossi et al. 2009). In this scenario, where financial resources and time to collect field data are scarce, the use of indicators, umbrella or keystone species (Simberloff 1998) 
has been proposed as a practical tool to conserve biodiversity in Natura 2000 sites. Woodpeckers, for instance, showing a strong affinity for forest and woodland and frequently relying on large and well conserved forest areas with large trees and deadwood, have often been considered as good indicators of forest biodiversity and their requirements used to identify appropriate forest management practices (Simberloff 1998, Fleishman et al. 2000, 2001, Mikusiński et al. 2001, Suter et al. 2002, Roberge and Angelstam 2004, Drever et al 2008, Roberge et al. 2008, Drever and Martin 2010).

The Black Woodpecker Dryocopus martius is a species of conservation interest, listed in Annex I of the Birds Directive and in the IUCN Red List of Threatened Species as 'Least Concern'. The Black Woodpecker is the largest woodpecker of the Palearctic Region and plays an important ecological role in European forest ecosystems as a keystone species for large-sized secondary cavity nesting birds (Johnsson 1993). In the Alps in particular, its nest cavities are used by Tengmalm's Owl Aegolius funereus for breeding and by Pygmy Owl Glaucidium passerinum for roosting and food storage (Gödecke and Rudat 1985); both species are listed in Annex I of the Birds Directive. Moreover, the presence of the Black Woodpecker has been found to be positively related to species diversity and relative abundance of a suite of alpine secondary cavity nesting birds (Pirovano et al. 2005).

In Europe the Black Woodpecker makes use of different habitats for breeding and feeding, (Cramp 1985). In Central Europe the species is considered by some authors as inhabitants of large managed forests and an indicator of old-growth conditions (Hölzinger and Kroymann 1981, Scherzinger 1981, 1989). In Spain too, the species has shown a preference for mature stands with older trees (Garmendia et al. 2006). However, studies carried out in Northern Europe have criticised the use of the Black Woodpecker as an indicator species of old-growth conditions, since feeding activity was also found in young plantations dominated by Norway spruce Picea abies and with high canopy closure (Rolstad et al. 1998). Moreover the species was found breeding in different habitats, from dense old forest stands, to single trees in large clear-cuts (Rolstad et al. 1998, 2000), including highly fragmented landscapes (Tjernberg et al. 1993). In a radio-telemetry study carried out in the western Alps, Bocca et al. (2007) suggested caution in considering the Black Woodpecker as a potential ecological indicator, because of its flexibility in habitat use and its adaptability to a variety of forest conditions. Likewise, nests have also been found in a large variety of tree species. In temperate forests of Central Europe, the Black Woodpecker uses broad-leaved deciduous trees such as beech Fagus sylvatica and lime Tilia cordata (Lang and Rost 1990). In Norway, the majority of nests were found in living aspen Populus tremula, Scots pine Pinus sylvestris and in dead trees (Rolstad et al. 200o). In the western Italian Alps, Black Woodpeckers mainly breed in beech and avoid mountain pine P. mugo forests (Bocca et al. 2007).

The Black Woodpecker appears to be a natural candidate as a focal species (sensu Armstrong 2002) useful to conserve bird diversity in Natura 2000 alpine sites, because of its important ecological role in forest ecosystems (Gorman 2011), its large home-range (Bocca et al. 2007, Kosiński and Kempa 2007), its wide distribution in the Alps and the ease with which it can be detected. Nonetheless, to date only a few studies have investigated its ecology in the Alps and in Natura 2000 sites (Pechacek 1995, Bocca et al. 2007).

The purpose of this study was to obtain information on forest features that influence the local habitat selection of Black Woodpeckers in three parks, located in the central and eastern Italian Alps, and included in the Natura 2000 network. To this end, we applied the habitat suitability model (HSM) approach to investigate the selection of cavity trees, feeding sites and the surrounding vegetation. The HSM approach attempts to investigate the relationship between an organism and its habitat, focusing on the environmental variables that have a direct ecological influence on the organism under study (Vaughan and Ormerod 2003), and to model these relationships with statistical methods. The resulting models, after careful validation, can then represent a valuable tool for conservation strategies (e.g. Mladenoff et al. 1999, Woolf et al. 2002). 
Using the HSM approach we tested the following null hypotheses: i) there is no difference in vegetation between woodpecker cavity trees and nearby trees; ii) there is no difference in vegetation between the forest surrounding cavity trees and random sites; and iii) there is no difference in vegetation between the forest surrounding feeding sites and random plots. Results are used to define management practices aimed at promoting the occurrence and the conservation of the Black Woodpecker and its co-occurring species.

\section{Methods}

\section{Study areas}

Field data were collected in three protected areas of the Italian Alps. The Sciliar-Catinaccio Natural Park (SCNP: 6,403 ha, 848-3,000 m asl) and the Vedrette of Ries Aurina Natural Park (RANP: $31,313 \mathrm{ha}, 893-3,485 \mathrm{~m}$ ), both located in the eastern Italian Alps (South Tirol, Province of Bolzano) and coinciding with the SACs and SPAs identified by the codes IT3110029 and IT3110017 respectively. The Orobie Valtellinesi Natural Park (OVNP: 46,200 ha, 900-3,052 m), corresponding to one SPA (5,959 ha; code: IT2040401) and II SACs (codes: IT2040026-IT2040036) and located in the central Italian Alps (Lombardy, Province of Sondrio). Parks are subject to a protective regime by the obligations arising under the Habitats Directive. Boundaries of Natura 2000 sites roughly correspond to the lower boundary of coniferous forests and parks are largely covered by acidophilus Picea forests (Vaccinio-Piceetea, code: 9410 Habitats Directive), dominated by Norway spruce and secondarily by larch Larix decidua and/or stone pine P. cembra forest (code: 9420 Habitats Directive) and scattered stands of silver fir Abies alba and Scots pine. In all parks, coniferous forests harbour both Tengmalm's Owl and Pygmy Owl, the two large-sized secondary cavity nesting birds listed in the Birds Directive that commonly use cavities excavated by the Black Woodpecker. The most common predator of the Black Woodpecker in these areas is the pine marten Martes martes, although the Goshawk Accipiter gentilis is also present.

\section{Cavity trees and feeding sites}

Areas in which the Black Woodpecker is present were identified using the playback method (Falls 1981) which has been widely used in field studies of different woodpecker species (e.g. Fernandez and Azkona 1996, Miranda and Pasinelli 2001, Kosiński et al. 2004). To provoke the response of territorial birds, taped-calls (Roche 1996), including advertising-calls, call notes, rattle-calls and drumming, were played every 250-500 m (according to topography), in the following manner: I-minute listening, 3 -minute playback sequence, I-minute listening, I-minute playback sequence, I-minute listening. After the first bird response the taped-calls were stopped to determine the initial location of the bird.

Cavity trees were identified by systematically walking through presence areas and looking for potential trees. In this study we considered any tree with one or more cavities excavated by Black Woodpeckers as a cavity tree, including confirmed nests (i.e. where breeding was in progress) and assumed cases (Rolstad et al. 200o). Assumed cases were defined as cavities completely excavated but not used for breeding at the moment of data collection. In fact, the Black Woodpecker frequently re-uses cavities over several years (Gorman 2011). The Black Woodpecker usually begins several cavities that are not always finished the same year and that, on average, are completed within 5-6 years (Zahner et al. 2012). To avoid the inclusion of false cavities (not completely excavated) all trees were examined with a micro-camera held up on a telescopic pole (maximum pole height: $12 \mathrm{~m}$ ). We also excluded from the analysis all those assumed cases showing recent signs of forest cutting within a radius of $25 \mathrm{~m}$ of the tree.

Foraging tracks were identified by walking at a fairly constant speed along 500-m transects and looking for foraging sites up to $50 \mathrm{~m}$ from transect lines (Savignac et al. 2000). A maximum of four feeding sites with fresh wood chips and at a minimum distance of $50 \mathrm{~m}$ from one another, 
were sampled in each transect (Savignac et al. 2000). When more than four suitable foraging tracks were found in a transect, feeding sites were selected to maximise the distance between observations. All transects ( 15 in Orobie Natural Park, 18 in Ries Aurina Natural Park and 20 in Sciliar-Catinaccio Natural Park) were located at a minimum of $50 \mathrm{~m}$ from roads to minimise potential edge effects (Savignac et al. 200o) and were walked once. None of the sampled sites overlapped. Only recent foraging sites with fresh wood-chips on the ground near the foraging site and with no signs of decay or fungi were considered.

\section{Vegetation survey}

The vegetation survey took place from 2002 to 2006. Habitat variables were measured between May and August during the snow-free season. The following variables were collected for each cavity tree and feeding site (i.e. living trees, dead standing trees and dead logs on which foraging tracks were identified): tree species (SP), canopy cover (CC), tree diameter at breast height (DBH), and tree crown height (TCRH) at the lowest crown branch. A diameter tape was used to take DBH measurements and TCRH was measured with a scale hypsometer. CC was measured by ocular (visual) estimation method, which uses a space-occupancy concept to estimate the area occupied by vegetation (Van Hees and Mead 2000). Four cover percentage values were attributed by an operator standing at each cardinal point at $1 \mathrm{~m}$ from the cavity tree or the feeding site being measured, and looking upwards to the zenith. Cover percentage referred to Braun-Blanquet (1928) scale were recorded as numbers from one to six $(1=<1 \%, 2=1-5 \%, 3=5-25 \%, 4=25-50 \%$, $5=50-75 \%$ and $6=75-100 \%$ ). The global CC was given by the average score of the four survey points. The same variables described above were also measured for the 12 trees $(\mathrm{DBH}>10 \mathrm{~cm})$ nearest to each cavity tree and foraging site. Further, the total number of trees ( $\mathrm{DBH}>10$ ), the volume of dead logs (diameter > 1o cm; LOGS) and the percentage of understory cover (UND), was measured in circular plots with a radius of $25 \mathrm{~m}$, centred on cavity trees and foraging sites. UND was estimated by visual inspection, using four density classes $(0-25,26-50,51-75$, and $76-100 \%$ ) and LOGS was calculated using length and mean diameter (measured at the midpoint of the dead $\log$ ). The total number of trees counted in each plot was used to estimate the number of trees per hectare, which was used as a proxy for the tree density (TD). In addition, we estimated the total basal area (BA) in $\mathrm{m}^{2} /$ ha of all trees visible from the centre of each plot using a relascope (Bitterlich 1984). This estimation is independent of the plot size as it uses an infinite-radius approach. The probability of trees being sampled is proportional to their size: a tree can be sampled because it is very large or, if small, very close to the sampling point.

Random plots were selected in portions of the study areas exhibiting high to mature forest conditions and were used for comparison to selected plots (i.e. plots centred on the cavity trees and feeding sites). Suitable forests were identified on a map with a $500 \mathrm{~m} \mathrm{x} 500 \mathrm{~m}$ overlapping grid system. Numbered squares were selected separately in each park, using a random number generator (sample function in R) with the constraint that selection of adjacent cells was not allowed. As close as possible to the centre of each selected square, a tree $(\mathrm{DBH}>10 \mathrm{~cm})$ was identified and a plot with a radius of $25 \mathrm{~m}$ was centred on it. CC, DBH, SP and TCRH were measured for the 12 trees $(\mathrm{DBH}>10 \mathrm{~cm})$ nearest to the centre of each random plot and BA, LOGS, TD and UND were also measured, as described above. Finally, dead/live status was recorded for cavity trees, foraging substrates and for the trees on random plots.

\section{Data partitioning and statistical analyses}

The assessment of model transferability from one study area to another is a key step in conservation practice. For this reason, the complete dataset was split into two parts. Data from Sciliar-Catinaccio Natural Park and Orobie Natural Park were merged and used for model construction (data set A), whereas data from Ries Natural Park were used for model validation (data set $B$ ). 
We used logistic regression analysis to investigate Black Woodpecker habitat selection. Of the GLM techniques, logistic regression is a frequently applied approach in modelling species distribution because it is flexible and robust. The link function in this type of GLM is logit and the error structure is assumed to be binomial (Collingham et al. 2000, Manel et al. 2001, Rushton et al. 2004). The correlation structure of measured variables was investigated before running the analysis. The Spearman's rank correlation coefficient was used to identify predictors that were highly correlated (rho > 0.7; Savignac et al. 2000, Pasinelli 2007). None of the predictor variables was found to be highly correlated to the others, so all were retained in the logistic regression analysis.

First, cavity trees were compared to the surrounding trees to assess which variables influence Black Woodpecker tree selection most. DBH, TCRH and CC were used as potential predictors in a logistic regression analysis to compare cavity trees to the average value of the 12 nearest trees. To evaluate the influence of forest context on woodpecker plot selection, we compared plots hosting cavity trees and feeding sites (hereafter also called 'cavity tree plots' and 'feeding site plots') to random plots. In this case, mean DBH, TCRH and CC averaged over the 12 nearest trees, and BA, LOG, TD and UND, were used as potential predictors in a logistic regression analysis. We fitted logistic regression models following a stepwise forward selection based on the log likelihood ratio (LLR) statistic (decision rule: $\alpha=0.05$ for entry and for removal). In logistic regressions, group membership was assessed using a threshold probability of 0.5 for the output variable (i.e. a fixed cut-off of $P=0.5$ ).

In addition, the univariate logistic regression model was used to estimate the probability of the occurrence of Black Woodpecker cavities in relation to the DBH of trees and to estimate critical values of DBH below which the probability of Black Woodpecker cavities drops below certain probability levels of interest. In this case, cavity trees were compared to trees surrounding them using the entire dataset $(\mathrm{A}+\mathrm{B})$.

The predictive performances of the final models were evaluated for both datasets A and B, by using the receiver operating characteristic (ROC) technique (Manel et al. 2001, Westphal et al. 2003, Rushton et al. 2004, Yamaura et al. 2005). This threshold-independent approach is based on plotting the true positive against the false positive fractions for a range of thresholds in predicting probability (Manel et al. 2001, Rushton et al. 2004). The area under the ROC plot curve (AUC) was taken as a measure of the accuracy of the models (Manel et al. 2001). The $95 \%$ confidence interval ( $95 \% \mathrm{CI})$ for each computed AUC was estimated on the basis of 10,000 replicates of nonparametric stratified bootstrap (Robin et al. 2011).

A chi-square goodness-of-fit test was performed, using the entire dataset $(A+B)$, to test whether cavity trees and foraging substrates were evenly distributed between dead and living trees, while Fisher's Exact Test assessed whether dead and living trees were used in proportion to their availability (represented by random plots). Finally, we applied contingency table analysis to explore relationships between tree species and different categories of tree. Five mutually exclusive categories were considered: 1 ) cavity trees; 2 ) feeding sites (i.e. living trees and identifiable dead standing trees, stumps and logs on which foraging tracks were recorded); 3 ) trees sampled in cavity tree plots (the 12 trees nearest to cavity trees); 4) trees sampled in feeding site plots (the 12 trees nearest to feeding sites) and 5) trees sampled in random plots (the 12 trees nearest to the centre of random plots). First, we examined the frequency distribution of tree species in relation to the first, third and fifth categories (hereafter indicated as'Crosstabi'). Then, the same analysis was carried out considering the second, fourth and fifth categories (hereafter indicated as'Crosstab2'). The entire dataset $(A+B)$ was used. Only those tree species with all expected frequencies higher than 2 and no more than $20 \%$ of expected frequencies below 5 , were included in the analysis (Yates et al. 1999). The Chi-Square Test of Independence was applied to test the null hypothesis of the overall independence of the rows and columns in the resulting 2-way tables. Standardised Pearson residuals were computed for each cell in the contingency tables and tested against a $z$ distribution to identify the cells that caused the rejection of the null hypothesis. The sequential Holm-Bonferroni correction of the significance threshold was applied to limiting 
the overall experiment-wise error rate. Results of contingency table analysis were visualised by means of mosaic plot technique (Meyer et al. 2006). All analyses and graphics were carried out using R v.2.12.o (R Development Core Team 2009) and pROC (Robin et al. 2011), ggplot2 (Wickham 2009), gmodels (Warnes et al. 2012) and vdc (Meyers 2006) packages.

\section{Results}

We identified a total of 94 cavity trees (27 in OVNP, 29 in RANP and 38 in SCNP). Cavities were not found in trees with a diameter at breast height of $<35 \mathrm{~cm}$. Altogether, we counted 30 active nests, but only $12(40 \%)$ were newly excavated. We also identified 90 feeding sites $(28$ in OVNP, 30 RANP and 32 in SCNP) and described 96 random plots (28 in OVNP, 30 in RANP and 38 in SCNP). Out of the 94 identified cavity trees, only four were found to be dead trees. Despite the significant disparity in counts $\left(\chi_{1}^{2}=78.681, P<0.0001, n=94\right)$, both dead and living trees were found to be used as cavity trees in proportion to their availability in random plots (Fisher's Exact Test: $P=1$, two-sided; sample estimate odds ratio: $1.171,95 \%$ CI: $0.418-4.545 ; n=1,246$ ). Foraging tracks were equally distributed between dead and living trees $\left(\chi^{2}{ }_{1}=0.711, P=0.399\right.$, $n=90$ ), but dead substrates were selected significantly more than would be expected from their availability in random plots (Fisher's Exact Test: $P<0.0001$ two-sided; sample estimate odds ratio: 15.987, 95\% CI: 9.484-27.017; $n=1,242$ ).

The highest significant pairwise correlation was found between DBH and TD (rho $=-0.54$, $P<0.001$ ) among the predictor variables. Logistic regression models built using dataset A (SCNP and OVNP), identified DBH and TCRH as significantly related to cavity tree (hereafter 'cavity tree model') and cavity tree plots (hereafter 'cavity plot model'; see Figure 1 and 2). Logistic regression also identified LOGS and UND as significantly related to feeding site plots (hereafter 'feeding site model'). Of the four significant predictors, only UND was found to be negatively
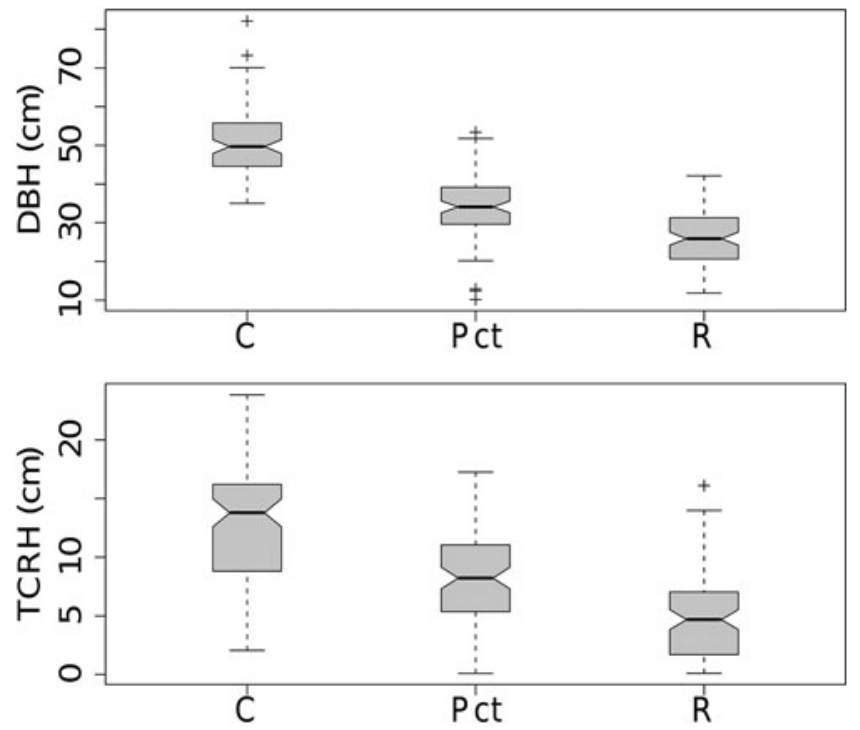

Figure 1 . Boxplots of diameter at breast height $(\mathrm{DBH})$ and tree crown height $(\mathrm{TCRH})$ variables recorded for cavity trees (C; $n=94)$, cavity tree plots (Pct; $n=94)$, and random plots $(\mathrm{R} ; n=96)$. The grey box represents the interquartile range with the median shown as a horizontal black line. The vertical lines represent the values included between the interquartile range \pm 1.5 times the interquartile range. Outliers beyond this are represented by ' + ' symbol. Data from Orobie, Ries Aurina and Sciliar-Catinaccio Natural Parks (dataset A+B; see text for details). 


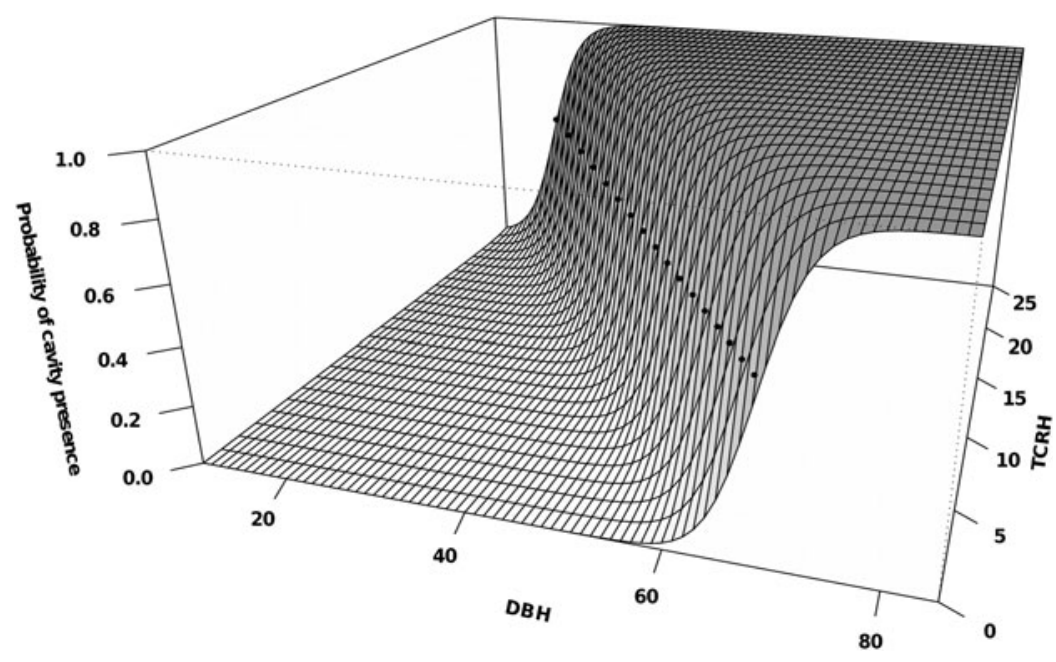

Figure 2. Probability surface of the bivariate logistic regression model showing the probability of cavity presence as function of the tree diameter at the breast height (DBH) and the tree crown height (TCRH; $n=130$ ). The regression coefficients of the model are shown in Table I (see 'cavity tree' model). Probability-based surface shading ranges from light shading for $P=0$ to dark shading for $P=1$. The thick dotted line represents the 0.5 threshold probability for the model.

related to Black Woodpecker presence (see Table I). ROC analysis to evaluate the discriminatory ability of the cavity tree model to distinguish between cavity trees and non-cavity trees resulted in an AUC value of 0.988 (95\% CI: 0.974-0.998), while the discriminatory ability of the cavity plot model to discriminate between cavity tree plots and random plots resulted in an AUC of 0.8669 (95\% CI: o.8-0.926). The feeding site model distinguishing between feeding sites plots and random plots, yielded an AUC of 0.708 (95\% CI: 0.618-0798; Tablex and Figure 3). The area under the ROC can be interpreted as the proportion of times a positive observation (i.e. a cavity tree, a cavity tree plot or a feeding site plot) is ranked with a higher probability than a negative observation (a non-cavity tree, or a random plot) for all pairs of positive and negative observations (Hosmer and Lemeshow 2000). As a rule of thumb, AUC values greater than 0.9 are considered to indicate high accuracy, values between 0.7 and 0.9 to indicate useful applications and values of $0.5-0.7$ to indicate low accuracy of the model (Manel et al. 2001, Yamaura et al. 2005). Model validation with dataset B (Ries Aurina Natural Park) yielded an AUC value of 0.817 (95\% CI: 0.7-0.912) in the case of the cavity tree model and an AUC of 0.754 (95\% CI: 0.617-0.874) for the cavity plot model. Thus, these two models behaved as 'useful applications' when also applied to the independent dataset. On the other hand, the AUC obtained by cross-validating the model used to discriminate between feeding site plots and random plots, was only 0.456 (95\% CI: 0.301-0.611), indicating overall that the model cannot be safely used in conservation practice (see Table 1 and Figure 3 ).

The univariate logistic regression model built using the entire dataset $(\mathrm{A}+\mathrm{B})$ and $\mathrm{DBH}$ as unique predictor (AUC: $0.929 ; 95 \%$ CI: 0.892-0.959), showed that the probability of a Black Woodpecker cavity in a tree, rapidly increases with increasingly values of DBH (see Figure 4 b). For example, the probability of Black Woodpecker cavity presence is only 0.2 when DBH is $\approx 36.9 \mathrm{~cm}$, but it increases to 0.5 if DBH is $\approx 42.1 \mathrm{~cm}$ and up to 0.9 if DBH is $\approx 50.2 \mathrm{~cm}$.

The overall Chi-Square Test of Independence rejected the null hypothesis of independence of the rows and columns in both contingency tables (Crosstabi: $\chi^{2} 8=381.728, P<0.0001, n=2,254$; Crosstab2: $\left.\chi^{2} 8=296.107, P<0.0001, n=2,222\right)$. Overall, only a single cell was found with expected frequency $<5$ in Crosstab2 analysis $(\approx 6.67 \%$; expected value $=3.949)$. Standardised Pearson residuals 
Table 1. Multivariate binary logistic regression models of presence/absence of Black Woodpecker cavities and feeding sites from recorded locations in Orobie and Sciliar-Catinaccio Natural Parks. Model selection was based on log likelihood ratio statistic (stepwise forward selection). B = regression coefficients; $n=$ sample size; $-2 \mathrm{LL}=-2 \mathrm{x} \log$-likelihood; $\Delta_{-2 \mathrm{LL}}=$ change in $-2 \mathrm{LL}$ if term removed from the model; AUC $=$ area under the ROC $_{\text {curve; }}{ }^{*}=P<0.05 ;{ }^{* *}=P<0.001 ;$ n.s. $=$ not significant; $\mathrm{SE}=$ standard error; $\mathrm{df}=$ degrees of freedom.

\begin{tabular}{|c|c|c|c|c|c|c|c|c|}
\hline Model & Predictor & $-2 L L$ & B & S.E. & $\Delta-2 \mathrm{LL}$ & $\mathrm{df}$ & AUC (95\%CI) & $\begin{array}{l}\text { Cross-validation } \\
\text { AUC }(95 \% \mathrm{CI})\end{array}$ \\
\hline \multirow{4}{*}{$\begin{array}{l}\text { Cavity tree } \\
\qquad(n=130)\end{array}$} & & 47.827 & & & & & 0.9885 & 0.8172 \\
\hline & $\mathrm{DBH}$ & & $0.317^{* * *}$ & 0.074 & $51.354^{* * *}$ & 1 & (0.974-0.9976) & $(0.7-0.9115)$ \\
\hline & TCRH & & $0.658^{* * *}$ & 0.1125 & $38.217^{* * *}$ & 1 & & \\
\hline & Constant & & $-21.955^{* * *}$ & $4 \cdot 768$ & & 1 & & \\
\hline \multirow{4}{*}{$\begin{array}{l}\text { Cavity tree } \\
\text { plot } \\
\quad(n=131)\end{array}$} & & 122.402 & & & & & 0.8669 & 0.754 \\
\hline & $\mathrm{DBH}$ & & $0.157^{* * *}$ & 0.035 & $26.860^{* * *}$ & 1 & $(0.8-0.9256)$ & $(0.6172-0.8736)$ \\
\hline & TCRH & & $0.235^{* * *}$ & 0.064 & $15.785^{* * *}$ & 1 & & \\
\hline & Constant & & $-6.321^{* * *}$ & 1.145 & & 1 & & \\
\hline \multirow{4}{*}{$\begin{array}{l}\text { Feeding site } \\
\text { plot } \\
(n=126)\end{array}$} & & 153.101 & & & & & 0.708 & 0.456 \\
\hline & UND & & $-0.018^{*}$ & 0.009 & $4.259^{*}$ & 1 & $(0.6178-07982)$ & (0.3012-0.6108) \\
\hline & LOGS & & $0.118^{* * *}$ & 0.034 & $18.930^{* * *}$ & 1 & & \\
\hline & Constant & & 0.325 n.s. & 0.539 & & $I$ & & \\
\hline
\end{tabular}

$\left(r_{\mathrm{sp}}\right)$ are approximately standard normal, which implies that the cells with $\left|r_{\mathrm{sp}}\right|>2$ and $\left|r_{\mathrm{sp}}\right|>4$ are those individually significant at approximately the $P=0.05$ and $P=0.001$ levels, respectively. However, to control the false positive error rate associated with performing multiple statistical tests, we applied the sequential Holm-Bonferroni correction, before assessing the significance of the cells. After the correction, several cells still showed a significant departure from expectation. Silver fir and larch were found to be positively associated with cavity trees $(z=7.272, P<0.0001$ and $z=5.085 P<0.0001$, respectively) with the silver fir also positively associated with cavity tree
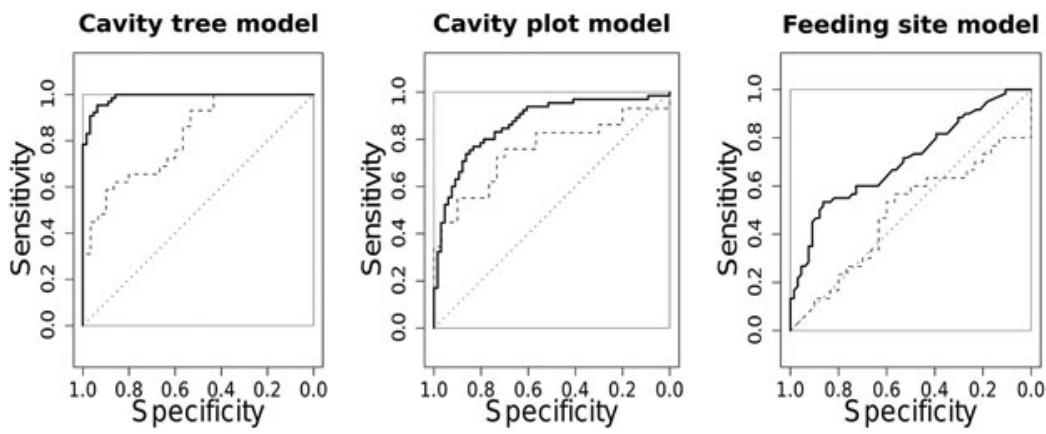

Figure 3. ROC curves: the area under the curve (AUC) was taken as a measure of the accuracy of logistic regression models built for cavity trees $(n=130)$, cavity tree plots $(n=131)$ and feeding site plots $(n=126$; see Table 1 ). The dotted light grey line represents the null model; the thick solid black line represents the predictive performance of the models evaluated using dataset $\mathrm{A}$ (model construction step); the thin dashed black line represents the predictive performances of the models evaluated using dataset B (model validation step; see text for details). 


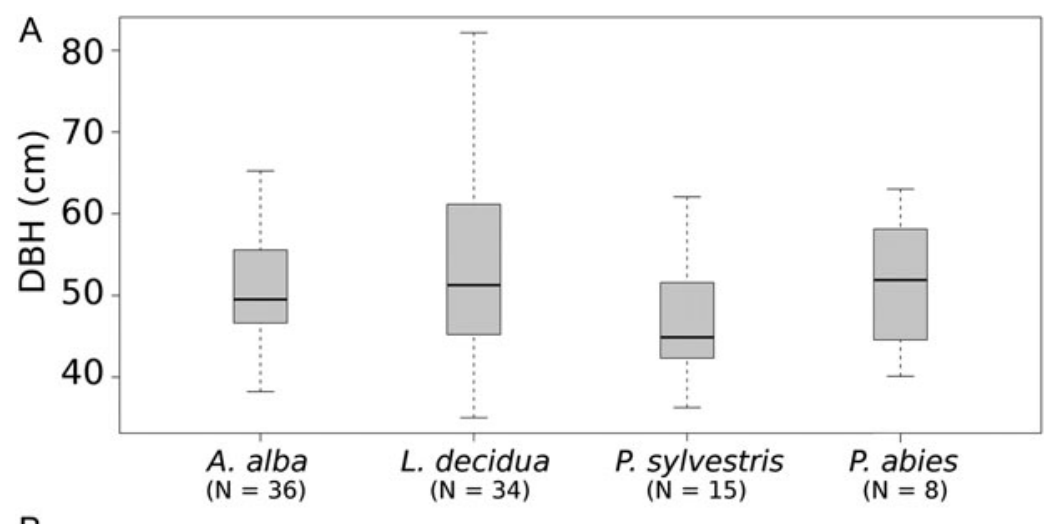

B
A. alba
. decidua
$(\mathrm{N}=15)$
$(\mathrm{N}=8)$

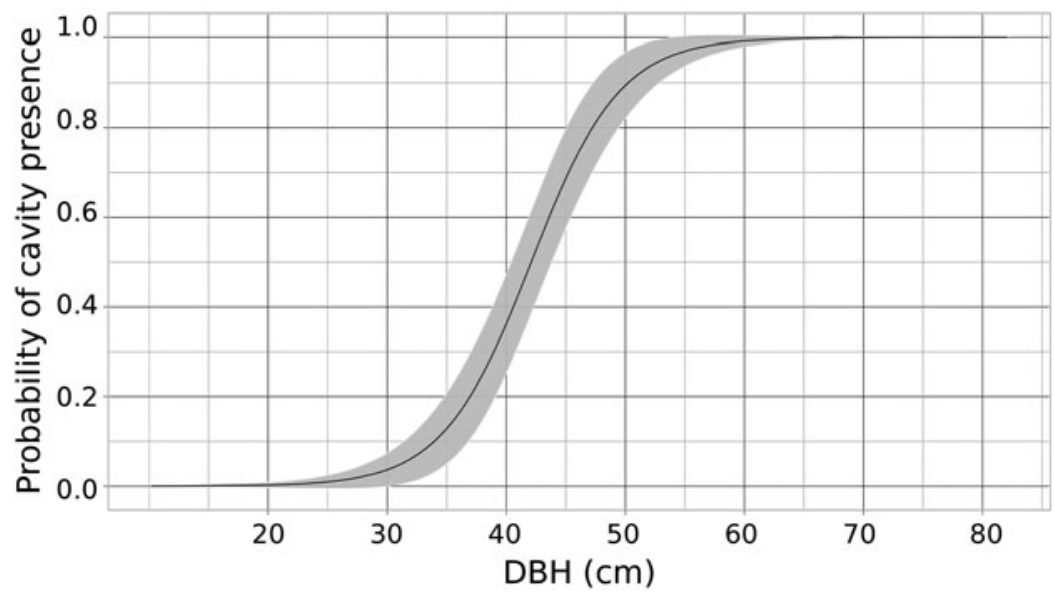

Figure 4. a) Boxplots of diameter at breast height (DBH) of the cavity trees species identified during our survey. The only cavity found in beech $(\mathrm{DBH}=55.7 \mathrm{~cm})$ is not shown. $\mathbf{b})$ The univariate logistic regression model ( $n=188$; model AUC: $0.929,95 \%$ CI: $0.892-0.960)$. This model was used to estimate the probability of occurrence of Black Woodpecker cavities as a function of DBH of trees, and to estimate critical threshold values for this variable using the following formula: $\ln (\mathrm{P} / 1-\mathrm{P})$ $=(0.270 \pm 0.038) \times \mathrm{DBH}+(-11.361 \pm 1.64)$, where $P$ is the probability of cavity presence (the black line in figure).The uncertainty is represented by the $95 \% \mathrm{CI}$ of the estimates (light grey in figure).

plots $(z=6.553, P<0.0001)$. Stone pine was negatively related to both cavity trees and cavity tree plots $(z=-3.045, P<0.05$ and $z=-7.056, P<0.0001$, respectively), while Norway spruce $(z=-5,579$, $P<0.0001)$ and Scots pine $(z=-3.182, P<0.05)$ were negatively related to cavity trees and to their plots, respectively (Crosstabi: see Appendix A in the online supplementary material and Figure 5). Scots pine and stone pine were also found to be negatively related to feeding site plots $(z=-5.492, P<0.0001$ and $z=-7.691, P<0.0001$, respectively) while silver fir and Norway spruce were positively associated with plots hosting feeding sites $(z=3.352, P<0.05$ and $z=$ 5.113, P < 0.0001 respectively; Crosstab2: see Appendix B and Figure 5). Results of contingency tables Crosstabi and Crosstab2 were illustrated using mosaic plots (see Figure 5). These area-proportional visualisations of observed frequencies, are composed of tiles (corresponding to the cells of the represented contingency table) created by recursive vertical and horizontal splits of a rectangle. The area of each tile is proportional to the corresponding cell entry conditioning on the dimensions of previous splits (Meyer et al. 2006). 

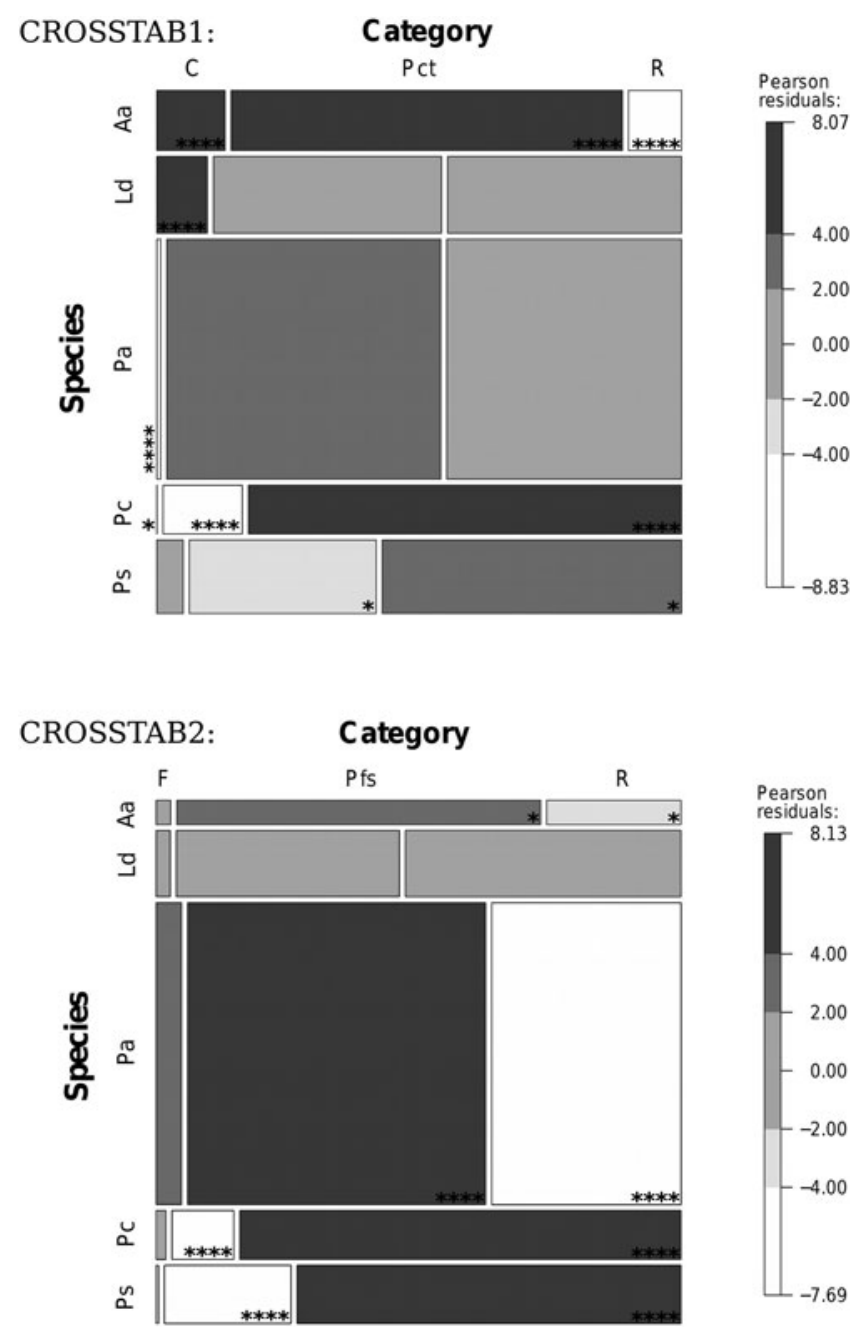

Figure 5. Mosaic plots were used for visualising the 2-way contingency tables Crosstabi and Crosstab2 (see text for details). Mosaic tiles are shaded according to their standardised Pearson residuals, as explained in figure. Tiles with a significant deviation from expectation after the sequential Holm-Bonferroni correction for multiple testing was applied, are marked with asterisks. $\mathrm{C}=$ cavity trees; $\mathrm{Pct}=$ trees sampled in cavity tree plots; $\mathrm{F}=$ feeding sites; $\mathrm{Pf}$ = trees sampled in feeding site plots; $\mathrm{R}=$ trees sampled in random plots; $\mathrm{Aa}=$ silver fir; $\mathrm{Ld}=$ larch; $\mathrm{Pa}=$ Norway spruce; $\mathrm{Pc}=$ stone pine; $\mathrm{Ps}=$ Scots pine; ${ }^{*}=\mathrm{P}<0.05 ;^{* * *}=P<0.0001$.

\section{Discussion}

\section{Cavity trees and surrounding vegetation}

By examining trees in the immediate area around Black Woodpecker cavity trees, our study showed that the average tree diameter and the average tree crown height in forest patches selected for cavity excavation were greater than the average values of the forests (here represented by random plots; see Figure 1 ). This suggests some preference for mature forest conditions, at least in the forest surrounding cavity trees. Our findings agree with results obtained in Spain by Garmendia 
et al. (2006), where the Black Woodpecker mainly selected mature stands with large and old trees. Bocca et al. (2007), in their work carried out in the western Italian Alps, also found that the Black Woodpecker positively selected forest stands with taller trees, though the species was found to be rather flexible in the use of habitats. In Norway, however, the species was found to breed mainly in suitable isolated trees retained in clear-cuts, presumably a strategy against predators such as the pine marten that avoid open habitats (Rolstad et al. 2000). Our results did not support a preference for isolated trees or open forests; however this difference may be due to the fact that in the studied areas, as well as in the Alps in general, large clear-cuts are rare, because of the risk of soil erosion and avalanches. Overall, this variation in habitat selection suggests a good adaptability of the Black Woodpecker to different forest conditions, as already also pointed out also by Rolstad et al. (2000) and Bocca et al. (2007).

We found that cavity trees were significantly larger in diameter and higher in crown height than the immediately surrounding trees. Affinity for large trees has already been pointed out (Rolstad et al. 2000, Garmendia et al. 2006 and references therein). Being the largest woodpecker species in the Western Palearctic, the Black Woodpecker needs large trees to excavate its nesting and roosting holes. However, our results show that trees selected to excavate holes were significantly larger than their nearby trees (mean DBH: $51 \mathrm{~cm}$ vs $34 \mathrm{~cm}$; see Figure 1). Although potentially the Black Woodpecker can use relatively small cavity trees - we have found a minimum diameter of $35 \mathrm{~cm}$ - we note that it selected much larger trees when they were available (up to a maximum of $82 \mathrm{~cm}$ in this study; see Figure 1 and Figure $4 \mathrm{a}$ ). Rolstad et al. (2000) proposed two possible explanations for this behaviour. First, large trees are less likely to break at the cavity. Second, cavities can be excavated higher up on large trees than on small trees, allowing the Black Woodpecker to observe predator attacks more efficiently. We also suggest that the selection of trees with few lateral branches below the cavity height (mean TCRH > I2 m; see Figure I), might be explained as anti-predator behaviour, probably allowing easier detection of predators and making it more difficult for predators, such as martens, to access the cavity. A similar explanation has been proposed by Nilsson et al. (1991) who proposed that the Black Woodpecker excavates holes in smooth-bark trees (e.g. beech) to protect its nest from tree-climbing predators such as the pine marten, the most important nest predator. Another possible explanation could be the death of lower branches following fungal infection (Zahner et al. 2012).

Most Black Woodpecker cavities identified in this work were excavated in silver fir $(n=36)$ and larch $(n=34)$, while the remaining cavities were found in Scots pine $(n=15)$, Norway spruce $(n=8)$ and beech $(n=1)$ (see Figure 4 a). Our results indicated that Black Woodpecker favours silver fir and larch as cavity trees, in the studied areas. The silver fir was also found to be positively associated with vegetation surrounding cavity trees. On the other hand, the Norway spruce was used less often than would be expected from its frequency in the studied areas (see Appendix A and Figure 5). This result agrees with Rolstad et al. (2000), who reported a marked avoidance of Norway spruce for nesting. Beech, in its natural range, is an important nesting tree for the Black Woodpecker (Bocca et al. 2007, Kosiński et al. 2010). However beeches are not widespread in the study areas, and this is probably why we found only one cavity excavated in beech.

Overall our results suggest a hierarchical pattern of habitat selection in the study areas. First, an appropriate forest sector is identified, then within a suitable forest patch, the Black Woodpecker selects the most suitable tree for cavity excavation. Our findings also suggest that the strongest selection regards the cavity tree, rather than surrounding vegetation. In this paper we have identified some tree traits (tree diameter, crown height and, to a lesser extent, tree species) that are most likely to influence cavity tree selection. However, other factors such as the presence of sufficient food supply or of fungal infections (heart rot fungi) are involved in cavity tree selection and may also have a considerable impact on the final choice (Rolstad et al. 2000, Zahner et al. 2012). Further studies are needed to explore the relative relevance of these issues in the study areas. 


\section{Feeding sites}

Our results indicate that the Black Woodpecker uses several species of trees for feeding, in proportion to their presence in the forests. Generally, forest patches with silver fir and Norway spruce were preferred over patches with Scots pine and stone pine, which were significantly avoided (Appendix B and Figure 5). Presence of feeding sites was positively associated with the amount of dead wood and negatively with the percentage of understorey cover. The preference for forests characterised by scarce understorey cover can probably be explained by the possibility of detecting food sources more easily. However the predictive power of the model, based on the amount of dead wood and the percentage of understorey cover, was low when applied to dataset B, and did not support its general validity. For the other forest variables, feeding sites did not differ from random sites. This suggests that Black Woodpecker also feeds in sites younger than sites hosting cavity trees. Young spruce forests normally host a large number of ant species, providing an important source of food, and are usually associated with a low proportion of understorey cover (Rolstad et al. 1998). Overall, the Black Woodpecker appears to behave as an opportunist, mainly choosing feeding sites on the basis of local forest conditions and food availability. This may explain the difficulties found in modelling its feeding preferences.

\section{Management implications}

As in Rolstad et al. (1998), we found that the Black Woodpecker mainly selects feeding sites like an opportunistic species. As already highlighted by other authors (Tjernberg et al. 1993, Rolstad et al. 1998, 2000, Mikusiński et al. 2001, Bocca et al. 2007), this suggests that the Black Woodpecker cannot be used as a specific indicator of old-growth conditions with respect to foraging site selection because of its adaptability to a variety of different forest types. On the other hand, our results have shown that the Black Woodpecker behaves as a demanding species when selecting its cavity sites in the Alps, and especially when selecting cavity trees (Figures $I$ and 3 ). It is important to note that, although the two predictors were both significantly selected in logistic regressions, the impact of DBH on the models is always higher than the effect of TCRH (Table 1, column $\Delta-2$ LL). Tree diameter can be monitored and managed by foresters much more easily than tree crown height. Nowadays, the knowledge of ecological thresholds for the amount of relevant habitat features is essential in the context of maintaining forest biodiversity and sustainable forest management (Bütler et al. 2004). The inflexion point (at $P=0.5$ ) of the univariate logistic model built on the entire dataset was $\approx 42 \mathrm{~cm}$, suggesting that below this tree diameter the probability of Black Woodpecker cavity presence drops quickly (actually reaching a value of 0.2 when tree diameter is just $\approx 37 \mathrm{~cm}$; Figure $4 \mathrm{~b}$ ). We did not find cavity trees $<35 \mathrm{~cm}$ in diameter in our study, and we observed a mean diameter of $51 \mathrm{~cm}$ that roughly corresponds to a threshold probability of $0.9(\approx 50 \mathrm{~cm})$. On the precautionary principle, we recommend that this threshold diameter is used to plan conservation strategies aiming to maintain the presence of Black Woodpeckers in the study areas.

The formation and persistence of tree cavities are key ecological processes that influence the abundance, diversity, and conservation of cavity-nesting and cavity-roosting vertebrates in forests (Cockle et al. 2011). As major creators of holes, woodpeckers are a keystone species whose presence provides a critical resource in the community of vertebrates that require, but cannot create, cavities and therefore they merit specific monitoring and management efforts (Kosiński and Kempa 2007, Drever and Martin 2010). The importance of the role of woodpeckers as hole providers for secondary users has been questioned by some authors (Wesołowski 2007, Cockle et al. 2011), who demonstrated that the importance of excavators may vary with forest type. However secondary medium-sized and large-sized cavity-users, such as Pygmy Owl and Tengmalm's Owl, could still strongly depend on the presence of woodpecker-made holes (Wesołowski 2007).

In our study areas, almost all Black Woodpecker-made cavities were found in coniferous trees indicating that Black Woodpecker may provide an important source of cavities in alpine forests largely dominated by coniferous trees where non-excavated holes develop at much lower rates 
than in deciduous forests (Waters et al. 1990). About 60\% of the active nests were found in old cavities. Nilsson et al. (1991) stated that Black Woodpeckers usually excavate a new nest cavity each year, mainly to avoid predation. Thus, our finding may be either a sign of shortage of such holes or a sign of a low predation rate in the studied area. However, other explanations are possible for the repeated use of old cavities. Gorman (2004, 2011) reported that when a new pair takes over a territory, it always excavates a new cavity, but as a rule, the Black Woodpecker frequently reuses cavities over years. Nest excavation is always a time and energy consuming investment that may involve the presence of heart rot fungi softening the wood and more than one year for completion (Zahner et al. 2012). Re-using available old cavities that show short-term stability of the tree trunk can considerably decrease energy expenditure, while still offering a good chance of nestling survival. Besides, since most of the cavities in this study were found in living conifers, the resin flow resulting from bark injuries may represent an additional issue for birds using new cavities. Actually, the differences in the anatomical complexity of the specialised resin secretory structures, ranging from multicellular resin blisters of firs (Abies spp.) to connected blisters of the genus Larix, and to the resin-filled network of highly branched and interconnected secretory ducts of pines (Pinus spp.) and spruces (Picea spp.; Phillips and Croteau 1999), suggest that the amount of resin flow resulting from cavity building can vary from species to species. In particular, silver fir, in which vertical resin ducts are absent from the secondary xylem (Stoffel 2008), may produce a limited resin flow compared to other conifers. In our study, in agreement with the anatomy of their resin secretory structures, Black Woodpecker significantly preferred silver fir and larch over pines and spruces. However, further investigation is needed to clarify this point.

Whatever the reason for the repeated use of old cavities, existing hollow-bearing trees are an important resource that should be carefully maintained for both the Black Woodpecker and secondary cavity-users. Nevertheless, in the study areas, trees with hollows are often lost because of accidental cuts or erroneously held beliefs of foresters and forest workers, thus affecting the availability of suitable cavity trees for the Black Woodpecker and secondary cavity-users.

All these considerations suggest that the Black Woodpecker is a species of primary interest for the maintenance of biodiversity in coniferous forests of the alpine ecosystem. On the basis of our results we developed a few forestry operation guidelines suitable for Black Woodpecker and secondary cavityusers, to be integrated into the management plans of alpine SACs and SPAs as conservation measures:

i) Rules and regulations: if not already required by forestry laws, it is necessary to introduce an explicit ban on cutting cavity trees, regardless of whether Black Woodpecker (or, by extension, another woodpecker species) is, or is not, using the tree for breeding at the time. This measure is necessary but not sufficient to prevent accidental cutting.

ii) Actions: to avoid the risk of accidental cutting, it is important to undertake geo-referencing and marking, with an easily identifiable sign at breast height, of each cavity tree. This method has been successfully applied in Switzerland to preserve cavities of the Great Spotted Woodpecker Dendrocopos major hosting Pygmy Owl (Henrioux et al. 2003) and in Trentino (Italy) to preserve cavities of Black Woodpecker and Grey-headed Woodpecker Picus canus, hosting Tengmalm's Owl and Pygmy Owl (Marchesi et al. 2008). It is worth remembering that the accidental cutting of cavity trees also has an economic implication since these trunks often have a reduced timber value. Moreover, at least some trees per hectare must be left to grow and be spared from forest cuttings to allow for the excavation of new cavities. On the basis of our results, we recommend that such trees, primarily silver firs and larches, have a minimum crown height of $>12 \mathrm{~m}$, and a minimum diameter at breast height of $>50 \mathrm{~cm}$.

iii) Environmental education: it is necessary to promote the knowledge of these issues through environmental education, aimed at anyone working in forests.

Similar operational guidelines have been included in the plans of management for SAC IT2040031 (Pirovano et al. 2010a) and SAC IT2040032 (Pirovano et al. 2010b), in the Orobie Valtellinesi Natural Park. 


\section{Supplementary Material}

The supplementary materials for this article can be found at journals.cambridge.org/bci

\section{Acknowledgements}

Thanks to: Wolfgang Schroeder and Ilse Storch, for their constructive suggestions during the planning phase of the project; Renato Sascor for supporting the project; Francesca Rogantini, Marco Ulivi and Monica Zen for their help with fieldwork. We are grateful to Penelope Barrington for improving our English and to the anonymous reviewers for their valuable comments that helped improve the manuscript. This research was funded by the Orobie Natural Park and the Office Nature Parks - Provincia Autonoma di Bolzano, Alto Adige.

\section{References}

Armstrong, D. P. (2002) Focal and surrogate species: Getting the language right. Conserv. Biol. 16: 285-286.

Bitterlich, W. (1984) The relascope idea: relative measurements in forestry. Slough, UK: Commonwealth Agricultural Bureau.

Bocca, M., Carisio, L. and Rolando, A. (2007) Habitat use, home ranges and census techniques in the Black Woodpecker Dryocopus martius in the Alps. Ardea 95: 17-29.

Braun-Blanquet, J. (1928) Pflanzensoziologie. Wien, Austria: Springer.

Bütler, R., Angelstam, P., Ekelund, P. and Schlaepfer, R. (2004) Dead wood threshold values for the three-toed woodpecker presence in boreal and sub-alpine forest. Biol. Conserv. 119: 305-318.

Cockle, K. L., Martin, K., and Wesołowski, T. (2011) Woodpeckers, decay, and the future of cavity-nesting vertebrate communities worldwide. Front. Ecol. Environ. 9: 377-382.

Collingham, Y. C., Wadsworth, R. A., Huntley, B. and Hulme, P. E. (2000) Prediction of the spatial distribution on nonindigenous weeds: issues of spatial scale and extent. J. Appl. Ecol. 37: $13-27$.

Cramp, S. ed. (1985) The birds of the Western Palearctic. Volume 4. Oxford, UK: Oxford University Press.

Drever, M. C., Aitken, K. E. H., Norris, A. R. and Martin, K. (2008) Woodpeckers as reliable indicators of bird richness, forest health and harvest. Biol. Conserv. 141: 624-634

Drever, M. C. and Martin, K. (2010) Response of woodpeckers to changes in forest health and harvest: Implications for conservation of avian biodiversity. For. Ecol. Manage. 259: 958-966.

European Commission (2003) LIFE FOCUS / LIFE for Natura 2000: 10 years implementing the regulation. Luxembourg: Office for Official Publications of the European Communities.

Falls, J. B. (1981) Mapping territories with playback: an accurate census method for songbirds. Stud. Av. Biol. 6: 86-91.

Fernandez, C. and Azkona, P. (1996) Influence of forest structure on the density and distribution of the White-backed Woodpecker Dendrocopos leucotos and Black Woodpecker Dryocopus martius in Quinto Real (Spanish western Pyrenees). Bird Study 43: 305-313.

Fleishman, E., Murphy, D. D. and Brussard, P. F. (2000) A new method for selection of umbrella species for conservation planning. Ecol. Appl. 10: 569-579.

Fleishman, E., Blair, R. B. and Murphy, D. D. (2001) Empirical validation of a method for umbrella species selection. Ecol. Appl. II: 1489-1501.

Garmendia, A., Cárcamo, S. and Schwendtner, O. (2006) Forest management considerations for conservation of Black Woodpecker Dryocopus martius and White-backed Woodpecker Dendrocopos leucotos populations in Quinto Real (Spanish Western Pyrenees). Biodiv. Conserv. 15: 1399-1415.

Gödecke, M. and Rudat, V. (1985) Zur Nutzung von Schwarzspechthöhlen durch den Sperlingskauz Glaucidium passerinum (L.). Acta Ornithoecol. 1: 87-90. 
Gorman, G. (2004) Woodpeckers of Europe: astudy of the European Picidae. Trowbridge, UK: Bruce Coleman Books.

Gorman, G. (2011) The Black Woodpecker - a monograph on Dryocopus martius. Barcelona: Lynx Edicions.

Hagan, J. M. and Meeham, A. L. (2002) The effectiveness of stand-level and landscape-level variables for explaining bird occurrence in an industrial forest. Forest Sci. 48: 231-242.

Henrioux, P., Henrioux, D. J., Walder, P. and Chopard, G. (2003) Effect of forest structure on the ecology of Pygmy Owl Glaucidium passerinum in the Swiss Jura Mountains. Vogelwelt 124: 309-312.

Hölzinger, J. and Kroymann, B. (1981) Resolution zum Schutz des Schwarzspechts. Beih.Veröff. Naturschutz Landschaftspflege Bad.-Württ. 20: 123.

Hosmer, D. W. and Lemeshow, S. (2000) Applied logistic regression. 2nd edition. New York: John Wiley and Sons.

Johnsson, K. (1993) The Black Woodpecker Dryocopus martius as a keystone species in the forest. Uppsala: Swedish University of Agricultural Sciences, Department of Wildlife Ecology, PhD dissertation.

Kosiński, Z., Kempa, M. and Hybsz, R. (2004) The accuracy and efficiency of different techniques for censusing territorial Middle Spotted Woodpeckers Dendrocopos medius. Acta Ornithol. 39: 29-34.

Kosinski, Z., and Kempa, M. (2007) Density, distribution and nest-sites of woodpeckers Picidae, in a managed forest of western Poland. Pol. J. Ecol. 55: 519-533.

Kosiński, Z., Bilińska, E., Dereziński, J. and Kempa, M. (2010) [The Black Woodpecker Drycocopus martius and the beech Fagus sylvatica as keystone species for the Stock Dove Columba oenas in western Poland]. Ornis Pol. 51: 1-13.

Lang, E. and Rost, R. (1990) Höhlenökologie und Schutz des Schwarzspechtes (Dryocopus martius). Vogelwarte 35: 177-185.

Manel, S., Williams, H. C. and Ormerod, S. J. (200I) Evaluating presence-absence models in ecology: the need to account for prevalence. J. App. Ecol. 38: 921-931.

Marchesi, L., Zanin, M. and Zorer, P. (2008) Lunga vita ai tronchi con il buco. Natura Alpina 1: 15-26.
Meyer, D., Zeileis, A. and Hornik, K. (2006) The strucplot framework: Visualizing multi-way contingency tables with vcd. J. Stat. Soft. 17: 1-48.

Mikusiński, G., Gromadzki, M. and Chylarecki, P. (2001) Woodpeckers as indicators of forest bird diversity. Conserv. Biol. 15: 208-217.

Mladenoff, D. J., Sickley, T. A. and Wydeven, A. P. (1999) Predicting gray wolf landscape recolonization: logistic regression models vs. new field data. Ecol. Appl. 9: 37-44.

Miranda, B. and Pasinelli, G. (2001) Habitatansprüche des Kleinspechts (Dendrocopos minor) in Wäldern der Nordost-Schweiz. J. Ornithol. 142: 295-305.

Nilsson, S. G., Johnsson, K. and Tjernberg, M. (1991) Is avoidance by Black Woodpeckers of old nest holes due to predators? Anim. Behav. 41: 439-441.

Pasinelli, G. (2007) Nest site selection in middle and great spotted woodpeckers Dendrocopos medius and D. major: implications for forest management and conservation. Biodiv. Conserv. 16: 1283-1298.

Pechacek, P. (1995) Spechte (Picidae) im Nationalpark Berchtesgaden. Habitatwahl, Nahrungsökologie, Populationsdichte. Berchtesgaden, Germany: Nationalpark Berchtesgaden (Research report 31).

Phillips, M. A. and Croteau, R. B. (1999) Resin-based defenses in conifers. Trends Plant Sci. 4: 184-190.

Pirovano, A., Zecca, G., Compostella, C. and Schroeder, W. (2005) The Black Woodpecker (Dryocopus martius) as focal species in alpine protected areas. Pp. $175-177$ in K. Bauch and G. Plassmann, eds. 3rd Symposium of the Hohe Tauern National Park for research in protected areas. Matrei in Osttirol (Austria): Hohe Tauern National Park Council and the Network of Alpine Protected Areas.

Pirovano, A. R., Zavagno, F., Pizzatti Casaccia, M., Brusa, G., Fioroni, M., Gasparini, L., Fumagalli, C., Scali, S. and D'Auria, G. (2010a) Piano di Gestione del SIC IT2040031. Val Cervia: Parco Regionale Orobie Valtellinesi. Pirovano, A. R., Zavagno, F., Pizzatti Casaccia, M., Brusa, G., Fioroni, M., Gasparini, L., Fumagalli, C., Scali, S. and D'Auria, G. (2010b) Piano di Gestione del SIC IT2040032. 
Valle del Livrio: Parco Regionale Orobie Valtellinesi.

Roberge, J. M. and Angelstam, P. (2004) Usefulness of the umbrella species concept as conservation tool. Conserv. Biol. 18: $76-85$.

Roberge, J. M., Mikusiński, G. and Svensson, S. (2008) The white-backed woodpecker: umbrella species for forest conservation planning? Biodiv. Conserv. 17: 2479-2494.

Robin, X., Turck, N., Hainard, A., et al. (2011) pROC: an open-source package for $\mathrm{R}$ and $\mathrm{S}+$ to analyze and compare ROC curves. BMC Bioinformatics, 7: 77 .

Roche, J-C. (1996) Bird songs and calls from Britain and Europe. Vol. III. Holt, Norfolk, UK: Wildsounds.

R Development Core Team (2009) R: A language and environment for statistical computing. Vienna, Austria: R Foundation for Statistical Computing. http://www.R-project. org.

Rolstad, J., Majewski, P. and Rolstad, E. (1998) Black Woodpecker use of habitats and feeding substrates in a managed Scandinavian forest. J. Wildl. Manage. 62: 11-23.

Rolstad, J., Rolstad, E. and Sǽteren, Ø. (2000) Black Woodpecker nest sites: characteristics, selection and reproductive success. J. Wildl. Manage. 64: 1053-1066.

Rossi, G., Parolo, G. and Ferrarini, A. (2009) A rapid and cost-effective tool for managing habitats of the European Natura 2000 network: a case study in the Italians Alps. Biodiv. Conserv. 18: 1375-1388.

Rushton, S. P., Ormerod, S. J. and Kerby, G. (2004) New paradigms for modelling species distributions? J. Appl. Ecol. 41: 193-200.

Savignac, C., Desrochers, A. and Hoult, J. (2000) Habitat use by Pileated Woodpeckers at two spatial scales in eastern Canada. Can. J. Zool. 78: 219.225.

Scherzinger, W. (1981) Zur Verbreitung des Schwarzspechtes (Dryocopus martius) im Nationalpark Bayerischer Wald. Beih. Veröff. Naturschutz Landschaftspflege Bad.-Württ. 20: 51-67.

Scherzinger, W. (1989) ['Endangered birdspecies of woodland, habitat pretensions and their integration in natural succession'.] Stapfia 20: 81-100. (In German with English summary).
Simberloff, D. (1998) Flagships, umbrellas, and keystones: is single-species management passé in the landscape era? Biol. Conserv. 83: $247-257$.

Stoffel, M. (2008) Dating past geomorphic processes with tangential rows of traumatic resin ducts. Dendrochronologia 25: $53-60$

Suter, W., Graf, R. F. and Hess, R. (2002) Capercaillie (Tetrao urogallus) and avian biodiversity: testing the umbrella-species concept. Conserv. Biol. 16: 778-788.

Tjernberg, M., Johnsson, K. and Nilsson, S. G. (1993) Density variation and breeding success of the Black Woodpecker in relation to forest fragmentation. Orn. Fenn. 70 : 155-162.

Van Hees, W. W. S. and Mead, B. R. (2000) Ocular estimates of understory vegetation structure in a closed Picea glaucal Betula papyrifera forest. J. Veg. Sci. I1: 195-200.

Vaughan, I. P. and Ormerod, S. J. (2003) Improving the quality of distribution models for conservation by addressing shortcomings in the field collection of training data. Conserv. Biol. 17: 1601-11.

Warnes, G. R, Bolker, B., Lumley, T., and Johnson, R. C. (2012) Package 'gmodels': Various $\mathrm{R}$ programming tools for model fitting. http://cran.es.r-project.org/web/ packages/gmodels/index.html.

Waters, J. R., Noon, B. R. and Verner, J. (1990) Lack of nest site limitation in a cavity-nesting bird community. J. Wildl. Manage. 54: 239-245.

Wesołowski, T. (2007) Lessons from longterm hole-nester studies in a primeval temperate forest. J. Ornithol. 148: 395-405.

Westphal, M. I., Field, S. A., Tyre, A. J., Paton, D. and Possingham, H. P. (2003) Effects of landscape pattern on bird species distribution in the Mt. Lofty Ranges, South Australia. Landsc. Ecol. 18: 413-426.

Wickham, H. (2009) ggplot2: elegant graphics for data analysis. New York: Springer.

Woolf, A., Nielsen, C. K., Weber, T. and GibbsKieninger, T. J. (2002) Statewide modeling of bobcat, Lynx rufus, habitat in Illinois, USA. Biol. Conserv. 104: 191-198.

Yamaura, Y., Katoh, K., Fujita, G. and Higuchi, H. (2005) The effect of landscape contexts 
on wintering bird communities in rural Japan. Forest. Ecol. Manage. 216: 187-200.

Yates, D., Moore, D. and McCabe, G. (1999) The practice of statistics. New York:W.H. Freeman.
Zahner, V., Sikora, L. and Pasinelli, G. (2012) Heart rot as a key factor for cavity tree selection in the Black Woodpecker. For. Ecol. Manage. 271: 98-103.

\section{ANDREA R. PIROVANO}

Progetto Natura, Cascinello Mako, Robecco sul Naviglio, Milano 20087, IT.

\section{GIOVANNI ZECCA*}

Department of Biosciences, Università degli Studi di Milano, Via Celoria 26, Milano 20133, IT.

*Author for correspondence; e-mail: giovanni.zecca@guest.unimi.it; giovanni.zecca@gmail.com

Received 27 July 2013; revision accepted 29 July 2013

Published online 24 February 2014 